\title{
INCLUSÃO NA EDUCAÇÃO SUPERIOR BRASILEIRA: ANÁLISE DA PRODUÇÃO CIENTÍFICA
}

\author{
INCLUSION IN BRAZILIAN HIGHER EDUCATION: ANALYSIS OF SCIENTIFIC \\ PRODUCTION
}

\author{
Josiane Pereira Torres ${ }^{1}$ \\ David dos Santos Calheiros ${ }^{2}$ \\ Vivian Santos $^{3}$
}

\begin{abstract}
Resumo
Dados censitários têm evidenciado o aumento no número de matrículas de alunos públicoalvo da educação especial no ensino superior. Esse estudo teve como objetivo analisar, por meio de uma revisão bibliográfica sistemática, o processo de inclusão na educação superior brasileira. A coleta de dados ocorreu no Portal de Periódicos da CAPES e os descritores usados para as buscas foram extraídos do Thesaurus Brasileiro da Educação. Foram selecionados para análise, na íntegra, 13 artigos. O procedimento de análise dos artigos consistiu em realizar a leitura dos textos na íntegra e no registro dos dados obtidos em um roteiro de análise. Os resultados apontam a escassez de pesquisas científicas nessa temática, contudo um aparente interesse maior nos últimos anos. Assim, vê-se a necessidade de explorar essa temática para que as principais dificuldades sejam evidenciadas, de modo a buscar melhores condições para garantir a plena inclusão no ensino superior.
\end{abstract}

Palavras-chave: Educação Especial. Ensino Superior. Inclusão.

\begin{abstract}
Census data have demonstrated the increase in the enrollments of target group of special education in the higher education. This study aimed to analyze, through a systematic literature review, the inclusion process in Brazilian higher education. The data collection was conducted through the CAPES Journal Portal, and the descriptors employed in the searches were extracted from the Brazilian Education Theusaurus. For the analysis were selected, full texts, 13 articles. To the analysis, the articles were read (full text) and, after, the collected data was registered from an analysis script. The obtained results points the research's scarcity about the subject, but a possible growing interest in the last years. Thus, it's necessary to explore the theme to these difficulties are evidenced, trying get better conditions to ensure full inclusion in higher education.
\end{abstract}

Keywords: Special Education. Higher Education. Inclusion.

\footnotetext{
${ }^{1}$ Doutoranda em Educação Especial pelo programa de Pós Graduação em Educação Especial da Universidade Federal de São Carlos E-mail: jtfisica@gmail.com

${ }^{2}$ Doutorando em Educação Especial pelo programa de Pós Graduação em Educação Especial da Universidade Federal de São Carlos. E-mail: davidcalheiros@hotmail.com

${ }^{3}$ Mestranda em Educação Especial pelo programa de Pós Graduação em Educação Especial da Universidade Federal de São Carlos. E-mail: vivi.eesp@gmail.com
} 


\section{INTRODUÇÃO}

Desde a década de 1960, a partir da luta pelos direitos humanos, começou a se discutir uma proposta com o objetivo de unificar a educação especial com a educação comum (MENDES, 2006). Tal movimento culminou em uma proposta de integração escolar, a qual propunha que os alunos com deficiência ${ }^{4}$ se adaptassem ao ambiente da classe comum, ideia essa que foi substituída, na década de 1990 pela inclusão escolar. A principal diferença entre esses modelos consiste no fato de que, na inclusão, é o ambiente que deve se adaptar ao aluno e não o contrário, demandando assim a reestruturação do sistema comum de ensino (JANNUZZI, 2006).

O debate acerca da inclusão escolar ganhou maior visibilidade internacional, por meio dos debates ocorridos na Conferência Mundial sobre Educação para Todos, em Jomtien/Tailândia, promovida pelo Banco Mundial, pela UNESCO (Organização das Nações Unidas para a Educação, Ciência e Cultura), pelo UNICEF (Fundo das Nações Unidas para a Infância) e pelo PNUD (Programa das Nações Unidas para o Desenvolvimento), os quais culminaram em consenso quanto à necessidade de haver concentração de esforços visando o atendimento das necessidades educacionais dos alunos, até então, privados do direito de acesso, permanência e sucesso na escola comum (MENDES, 2006). Em seguida, na "Conferência Mundial sobre Necessidades Educacionais Especiais: acesso e qualidade" foi elaborada a Declaração de Salamanca, que amplificou ainda mais o debate sobre a inclusão escolar.

No Brasil, o debate se materializou através dos marcos-legais, dentre os quais se tem, principalmente, a Constituição Federal de 1998 (BRASIL, 1988) e a Lei 9.34/96, a Lei de Diretrizes e Bases da Educação (BRASIL, 1996). Ambas pontuavam a possibilidade de inclusão no ensino comum do alunado da educação especial, com direito ao atendimento educacional especializado (AEE), sendo que a primeira restringia seu público aos alunos com deficiência, enquanto a segunda já considerava, em tese, todos os alunos PAEE. Cabe destaque ao fato de que a adoção do termo preferencialmente para se referir a esta inclusão dava margem para a colocação dos alunos PAEE em espaços segregados de ensino. Além disso, também não se discutia nada sobre a efetivação do serviço de AEE, o que é uma

\footnotetext{
${ }^{4}$ Primeiramente tal discussão se restringia as pessoas com deficiência. Com o passar do tempo, o público atendido foi expandido e, no Brasil, atualmente, considera-se como alunado da educação especial as pessoas público alvo da educação especial (PAEE), ou seja, pessoas com deficiência, transtornos globais do desenvolvimento e/ou altas habilidades/superdotação.
} 
problemática a ser considerada, uma vez que a inclusão escolar demanda a criação de serviços de apoio pedagógico para os alunos PAEE.

Foi somente a partir de 2003, com a entrada de novos quadros políticos no âmbito federal, que teve início à implantação de diversos programas ${ }^{5}$ e ações de cunho social, dentre os quais estão àqueles destinados a promoção de acesso escolar às classes comuns para os alunos PAEE (KASSAR, 2012). Cabe pontuar que este cenário foi consonante com o internacional, materializada através de novos encontros e acordos internacionais, em meio os quais se destaca a Convenção Internacional dos Direitos das Pessoas com Deficiência, em março de 2007.

Nesse sentido, em relação à efetivação de uma política com vistas à inclusão escolar, no Brasil, evidenciou-se o Programa de Implantação das Salas de Recursos Multifuncionais (SRM), iniciado em 2005; a promulgação de um documento norteador para a política em questão, denominado de Política Nacional de Educação Especial na perspectiva da Educação Inclusiva (BRASIL, 2008a), em 2008; e também da primeira legislação que descrevia o serviço de AEE, o Decreto 6.571/2008 ${ }^{6}$ (BRASIL, 2008b).

Nesse contexto, o serviço de AEE torna-se uma realidade em todo o Brasil, cujo espaço consiste nas SRM, devendo se dar no contra turno da escola comum. Estudos como os desenvolvidos pelo Observatório Nacional de Educação Especial (ONEESP) ${ }^{7}$, vêm demonstrando que a inclusão escolar está ocorrendo, principalmente em termos de acesso, porém ainda há muito para a se fazer em relação à permanência e sucesso escolar desses alunos. Sucesso este que implicaria na possibilidade do discente PAEE realizar um curso de nível superior. Castanho e Freitas (2006) defendem que todos os contextos educacionais, logo, as Instituições de Ensino Superior (IES), devem promover a cidadania e, consequentemente, possuem a obrigação de criar oportunidades e incentivar uma educação para todos.

\footnotetext{
${ }^{5}$ Os programas destinados a criação e efetivação de uma proposta de inclusão escolar consistiram em: "Programa Nacional de Formação Continuada de Professores na Educação Especial e Formação de Professores para o Atendimento Educacional Especializado (...); Programa de Implantação de Salas de Recursos Multifuncionais (...); Escola Acessível; Programa Educação Inclusiva: Direito à Diversidade (...); Programa Incluir (...).” (KASSAR, 2012, p. 101).

${ }^{6}$ Atualmente revogado pelo Decreto 7.611/2011 (BRASIL, 2011).

${ }^{7}$ O ONEESP consiste em um estudo elaborado em rede e de âmbito nacional, cujo objetivo consiste na avaliação do Programa de Implantação das SRM , criado pela Secretaria de Educação Especial do Ministério da Educação (MEC), o qual, desde 2005, apoia a criação e expansão do serviço de AEE (MENDES; CIA, 2012). As publicações elaboradas dentro do contexto deste estudo podem ser encontradas nos relatórios do estudo, disponíveis no seguinte site: http://www.oneesp.ufscar.br/publicacao-do-oneesp
} 
Sobre a inclusão no ensino superior, Sassaki (2006) pontua que, atualmente, há convergência entre duas tendências que antes se davam de forma distinta: o aumento da quantidade de alunos com deficiência que estão frequentando cursos superiores e a adoção de medidas para atender as necessidades desses alunos, sendo que tais necessidades são de dois âmbitos, a saber: medidas de ingresso e de permanência no curso escolhido.

Em relação ao ingresso, as medidas são relacionadas à adaptação das avaliações para as necessidades do discente. Já sobre a permanência, são necessárias medidas para sanar as barreiras: atitudinais advindas dos professores e colegas; arquitetônicas, relacionadas às instalações da universidade; orais, da comunicação com os pares e docentes; e técnicas, como, por exemplo, dificuldade para fazer anotações, apresentar tarefas em casa entre outros (SASSAKI, 2006). Além disso, visando eliminar tais barreiras, a formação dos docentes que atuarão com este público precisa ser pensada e modificada.

Em termos legais, a inclusão de alunos PAEE possui respaldo, nas universidades federais, da Política de Acessibilidade nas Instituições Federais de Educação Superior, a qual regulamenta o programa Incluir, cujo objetivo é:

Fomentar a criação e a consolidação de núcleos de acessibilidade nas universidades federais, as quais respondem pela organização de ações institucionais que garantam a inclusão de pessoas com deficiência à vida acadêmica, eliminando barreiras pedagógicas, arquitetônicas e na comunicação e informação, promovendo o cumprimento dos requisitos legais de acessibilidade (BRASIL, 2013, p. 3).

O programa Incluir vai ao encontro de sanar as barreiras para permanência no ensino superior, ele possui abrangência sobre as universidades públicas. Além do documento supracitado, as universidades precisam considerar diversas legislações que contemplam: a educação como direito para todos (BRASIL, 1988); o reconhecimento da Língua Brasileira de Sinais (LIBRAS) como língua (BRASIL, 2002); normas e critérios para ao atendimento prioritário a acessibilidade para pessoas com deficiência ou mobilidade reduzida (BRASIL, 2004); a existência de um intérprete de LIBRAS para alunos surdos, bem como, o ensino da língua através de uma disciplina obrigatória para os cursos de formação de professores e fonoaudiologia e optativa para os demais cursos (BRASIL, 2005); a garantia de educação para todos os alunos em todos os níveis de ensino (BRASIL, 2009); e, a estruturação de núcleos de acessibilidade nas instituições federais de ensino superior (BRASIL, 2011).

Logo, nota-se que, atualmente, há considerável aparato legal para garantir a diminuição e, inclusive, a eliminação das barreiras existentes. Ao mesmo tempo, os dados censitários têm demonstrado que há grande aumento no número de matrículas de alunos 
PAEE no ensino superior (crescimento, no total, de 358\% de 2011 em relação ao ano de 2003). Porém, é necessário questionar: as instituições de ensino superior estão conseguindo garantir a permanência e sucesso escolar desses alunos?

Visando responder esse questionamento, realizou-se o presente estudo, cujo objetivo foi analisar por meio de uma revisão bibliográfica sistemática o processo de inclusão na educação superior brasileira.

\section{PERCURSO METOdOLÓGICO}

O presente estudo consiste em uma revisão bibliográfica sistemática, do tipo integrativa. De acordo com Botelho, Cunha e Macedo (2011) esse tipo de estudo faculta obter um panorama sobre a produção científica, proporcionando conhecimento sistematizado sobre a evolução de um tema - ao longo do tempo, e possibilidades para estudos futuros.

A pesquisa foi realizada na base de dados do Portal de Periódicos da $\mathrm{CAPES}^{8}$, pelo fato de agregar um elevado número de produções - tanto nacionais quanto internacionais, mais de 37 mil títulos, referentes a 126 bases de dados.

Os descritores utilizados foram extraídos do Thesaurus Brasileiro da Educação (Brased), a saber: Educação superior; Professores de Educação superior; Instituições de Ensino Superior; Ensino Superior; Educação Especial; Educação Inclusiva. Pelo fato da finalidade do estudo ser de revisar produções nacionais, não foram adotados descritores em língua estrangeira. Reitera-se que foram realizadas combinações dos descritores acima pontuados com o auxílio do indicador booleano AND.

Como critérios de elegibilidade para a presente revisão foram estabelecidos: artigos em língua portuguesa, que tratassem da inclusão escolar de alunos PAEE na educação superior brasileira, tendo como critérios de inclusão possuir acesso livre e serem pesquisas de campo.

Adotando os critérios supracitados, localizou-se 37 artigos no total. No entanto, desta seleção inicial foram excluídos: seis artigos que não abordavam a temática central da investigação; cinco artigos que não tratavam da inclusão na educação superior brasileira; e nove artigos que se enquadravam como estudos de revisão, documentais ou ensaios teóricos.

\footnotetext{
8 Para conhecer mais sobre o Portal de Periódico da Capes, viste seu site: http://www.periodicos.capes.gov.br/index.php?option=com_pcontent\&view=pcontent\&alias=missaoobjetivos\&Itemid=102.
} 
Por fim, foram considerados para análise, na integra, 13 artigos. O processo de seleção dos artigos pode ser visualizado na Figura 1.

Figura 1 - Processo de seleção dos artigos

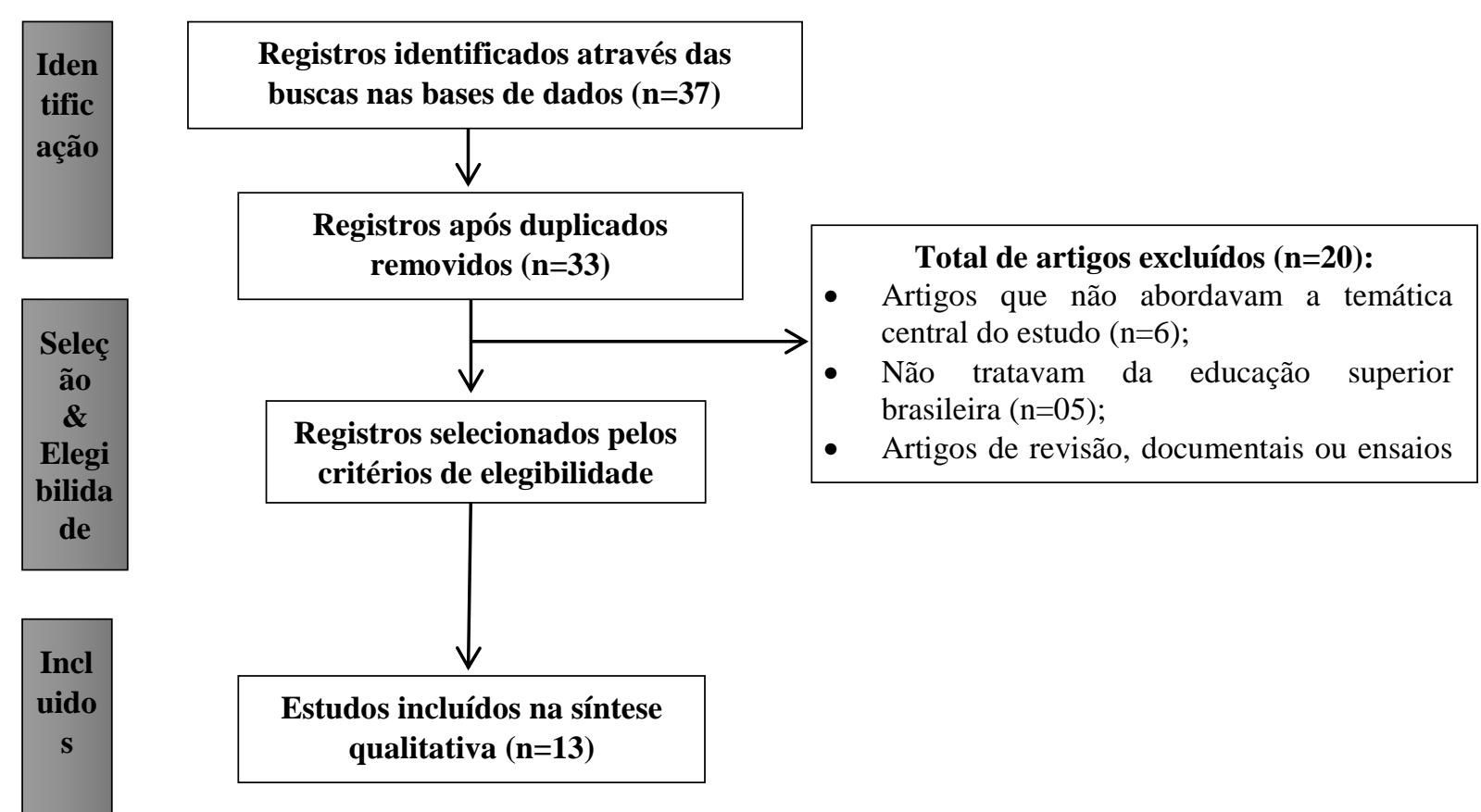

Fonte: Elaboração própria.

O processo de busca e seleção dos artigos ocorreu durante o mês de outubro de 2015, sendo realizado por um dos pesquisadores. Dois juízes independentes, utilizando-se dos mesmos procedimentos estabelecidos, conduziram uma revisão e validaram a coleta - uma vez que não houve divergência entre a busca do pesquisador e a dos juízes.

O procedimento de análise dos artigos consistiu em realizar a leitura dos textos na íntegra e no registro dos dados obtidos em um roteiro de análise, o qual foi elaborado para este fim. O roteiro permitiu compilar as seguintes informações: nome do(s) autor(es), ano de publicação, título da obra, objetivo do estudo, local, abordagem metodológica e os principais resultados dos artigos.

\section{RESULTADOS E DISCUSSÕES}

O quadro 1 apresenta a síntese das informações obtidas nesse estudo. Inicialmente pode-se discutir a pouca produção científica que reporta essa temática, mas vale pontuar que 
outros trabalhos não participaram desta revisão devido aos critérios estabelecidos. Quanto ao ano de publicação, pode-se dizer que as pesquisas são relativamente recentes, o que é coerente com a publicação dos documentos e leis que norteiam a atual política de inclusão escolar. Dois estudos foram publicados no ano de 2007, outros dois no ano de 2008, um estudo no ano de 2009, dois no ano de 2010, um no ano de 2011, não foram encontrados estudos no ano de 2012, por meio dos critérios estabelecidos. Encontrou-se dois estudos no ano de 2013 e três no ano de 2014. Nesse percurso, nota-se que a quantidade de artigos publicados se mantém constante e uma tendência de aumento no ano de 2014, indicando um possível maior interesse dos pesquisadores por essa temática.

Com relação à coleta de dados, nota-se que o roteiro de entrevista foi o instrumento mais utilizado, seguido pelo questionário. Acredita-se que isso ocorreu pois estes instrumentos possibilitam contato direto e, consequentemente, maior volume de dados, com os principais sujeitos envolvidos no processo de inclusão, ou seja, principalmente, discentes PAEE incluídos no ensino superior.

Após a leitura e análise dos artigos que compõe essa revisão emergiram quatro categorias que descrevem os resultados. São elas: "Formação docente e inclusão no ensino superior", "Entraves para a inclusão no ensino superior", "Perfil dos discentes PAEE incluídos no ensino superior" e "outras informações relevantes”. 


\section{Quadro 1 - Síntese dos dados obtidos}

\begin{tabular}{|c|c|c|c|c|}
\hline Autor/Ano ${ }^{9}$ & Objetivo & Participantes & $\begin{array}{c}\text { Coleta de } \\
\text { dados }\end{array}$ & Principais Resultados \\
\hline $\begin{array}{l}\text { (MARQUES } \\
\text {; GOMES } \\
\text { 2014) }\end{array}$ & $\begin{array}{l}\text { Caracterizar na concepção de } \\
\text { docentes universitários a } \\
\text { concordância sobre a inclusão } \\
\text { de alunos com deficiência, } \\
\text { transtornos globais do } \\
\text { desenvolvimento } \\
\text { superdotação no ensino } \\
\text { superior }\end{array}$ & $\begin{array}{l}20 \text { professores do ensino } \\
\text { superior de } \text { uma } \\
\text { Universidade Federal da } \\
\text { região Sul Mineira. }\end{array}$ & $\begin{array}{l}\text { Questionário } \\
\text { composto por } \\
\text { questões } \\
\text { abertas e } \\
\text { fechadas }\end{array}$ & $\begin{array}{l}\text { Os dados obtidos foram analisados quantitativamente por meio de } \\
\text { provas estatísticas descritivas } \\
\text { - dos } 20 \text { professores entrevistados, } 11 \text { nunca participaram de algum } \\
\text { cursou ou palestra sobre a Inclusão Educacional de alunos com NEE; } \\
\text { - dos } 20 \text { professores entrevistados, } 12 \text { nunca lecionaram para estes } \\
\text { alunos; } \\
\text { - dos } 20 \text { professores entrevistados, } 16 \text { consideram ser de sua } \\
\text { responsabilidade a atuação em salas de aula inclusivas; } \\
\text { - dos } 20 \text { professores entrevistados, } 13 \text { não conhecem nenhum processo } \\
\text { de inclusão escolar ofertado a estes alunos. }\end{array}$ \\
\hline $\begin{array}{l}\text { (CAMBRUZ } \\
\text { ZI; COSTA; } \\
\text { DENARI, } \\
\text { 2013) }\end{array}$ & $\begin{array}{l}\text { Identificar e verificar o } \\
\text { deslocamento nas rotas e } \\
\text { rotinas estabelecidas por um } \\
\text { universitário (cadeirante) e, } \\
\text { propor acesso alternativo } \\
\text { disponível para torná-lo } \\
\text { acessível. }\end{array}$ & $\begin{array}{l}\text { Um estudante universitário, } \\
\text { com deficiência física. }\end{array}$ & $\begin{array}{l}\text { - Observações; } \\
\text { - Registros } \\
\text { através de } \\
\text { fotografias e } \\
\text { filmagens. }\end{array}$ & $\begin{array}{l}\text { - há necessidades de alterações para propiciar à acessibilidade com } \\
\text { segurança e comodidade, assim como, estabelecer mecanismos para } \\
\text { que a biblioteca comunitária e o restaurante universitário } \\
\text { façam parte da vivência como integrante da comunidade universitária } \\
\text { e, também, no exercício de seus direitos constitucionais. }\end{array}$ \\
\hline $\begin{array}{l}\text { (LACERDA; } \\
\text { GURGEL, } \\
\text { 2011) }\end{array}$ & $\begin{array}{l}\text { Conhecer o perfil daqueles } \\
\text { que vêm atuando como } \\
\text { tradutores-intérpretes de } \\
\text { Libras no Ensino Superior no } \\
\text { Brasil }\end{array}$ & $\begin{array}{l}37 \text { tradutores-intérpretes de } \\
\text { Libras. }\end{array}$ & $\begin{array}{l}\text { Roteiro de } \\
\text { entrevista } \\
\text { virtual }\end{array}$ & $\begin{array}{l}\text { - } 70 \% \text { dos entrevistados referiram atuar em instituições privadas; } \\
\text { - a maioria dos participantes passaram por algum tipo de formação em } \\
\text { Libras, mas menos da metade fez formação específica para atuar como } \\
\text { TILS; } \\
\text { - } 35 \% \text { dos entrevistados tem formação em Pedagogia, } 13 \% \text { em } \\
\text { Fonoaudiologia e } 4 \% \text { em Educação Especial, num total de } 52 \% \text { dos } \\
\text { entrevistados; } \\
\text { - } 68 \% \text { têm certificados pelo Prolibras e } 32 \% \text { não; } \\
\text { - dos entrevistados } 41 \% \text { refere ter se tornado intérprete pelo contato } \\
\text { com surdos dentro de espaços religiosos. }\end{array}$ \\
\hline $\begin{array}{l}\text { (DUARTE, } \\
\text { et al. 2013) }\end{array}$ & $\begin{array}{l}\text { Levantar o número de alunos } \\
\text { autodeclarados } \\
\text { deficiência em processo de } \\
\text { inclusão no ensino superior }\end{array}$ & $\begin{array}{l}21 \text { coordenadores de oito } \\
\text { IES particulares e } 35 \\
\text { coordenadores dos cursos } \\
\text { oferecidos pela IES pública. }\end{array}$ & $\begin{array}{l}\text { Roteiro de } \\
\text { entrevistas e } \\
\text { questionário } \\
\text { sociodemográf }\end{array}$ & $\begin{array}{l}\text { - Encontrou-se } 45 \text { alunos com deficiência matriculados e frequentes } \\
\text { em cursos de ensino superior da cidade. A rede privada representa } \\
82,2 \% \text { desse total e a rede pública federal, } 17,8 \% \text {. }\end{array}$ \\
\hline
\end{tabular}

\footnotetext{
${ }^{9}$ As informações completas dos artigos podem ser obtidos na sessão de Referências.
} 
nas instituições públicas e privadas de Juiz de Fora

(DUARTE; Realizar um levantamento dos

FERREIRA, alunos com deficiência em 2010) processo de inclusão no superior em Juiz de Fora, MG

CRUZ; condições dos alunos surdos na escola, especificamente no ensino superior, sob o ponto de vista desses alunos e sob a perspectiva sócioantropológica da surdez 2008)

Compreender o processo de implantação de cotas provenientes das ações afirmativas, no Ensino
Superior, como possível contribuição para a inclusão do aluno com deficiência na Universidade.

\section{(MANENTE Compreender os fatores} ; diferenciais que podem RODRIGUE $\mathrm{S}$; PALAMIN 2007) ingresso de indivíduos com deficiência auditiva no ensino deficiência auditiva no ensino curso.

Nas IES privadas: contavam à época da pesquisa c om aluno auto declarados com deficiência regularmente matriculado e frequente; $\mathrm{Na}$ IES pública: todos os coordenadores dos 45 cursos oferecidos;

Sete surdos universitários.

Entrevistas individuais sucessivas, presenciais ou à distância.

16 alunos com deficiência física, auditiva e visual, e dez gestores

Universidade. de. qualitativa;

- entrevistas

semiestruturad as individuais.

69 pacientes do Centro dos - dois

Distúrbios da Audição, questionários:

Linguagem e Visão, do Grupo

Hospital de Reabilitação de Universitários

Anomalias Craniofaciais, da e B1-com

Universidade de São Paulo, ensino médio;

em Bauru/SP

B2 - outra

escolaridade coordenadores de cursos que

Os dados apontam a existência de 45 alunos com deficiência matriculados e frequentes em cursos nas IESs públicas e privadas. Sendo $82,2 \%$ (37 alunos) pertencentes à rede privada e 17,8\% (8 alunos) da rede pública. A maioria das matrículas desses alunos com deficiência concentra-se na área de Humanidades

- Os participantes discutem a comunicação como dificuldade para a inclusão no ensino superior;

- as condições dos surdos no ensino superior são de dificuldades, de impedimentos, de abandono e de rejeição;

- o sistema de avaliação são excludentes, pois são em português sem interprete;

- os alunos entrevistados apontam maior flexibilidade no processo avaliativo;

- os alunos enfrentam dificuldades em função da falta de suporte e apoio, no que se refere as suas limitações, por parte da instituição.

- A falta de acessibilidade nos transportes, os locais de embarque afastados e os horários limitados são dificuldades enfrentadas pelos alunos;

- Relatam ainda a ausência de acessibilidade e adaptações física;

GRUPO $\mathrm{A}^{10}$ : os participantes desse grupo relataram que os aspectos favorecedores para o ingresso no curso superior foram: ter tido sucesso na vida escolar anterior, ajuda da família e apoio dos professores.

Grupo A: quatro alunos - abordagem

\footnotetext{
${ }^{10}$ Foram apresentados apenas os resultados relacionados ao grupo que havia ingressado no ensino superior devido ao objetivo dessa pesquisa.
} 


\begin{tabular}{|c|c|c|c|c|}
\hline 2014) & 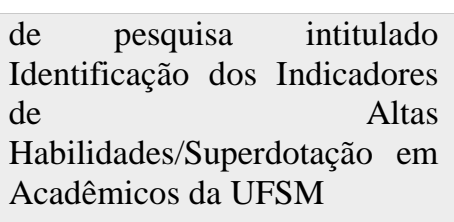 & $\begin{array}{l}\text { sendo duas mulheres e dois } \\
\text { homens. Grupo B quatro ( } 4 \text { ) } \\
\text { acadêmicas. }\end{array}$ & $\begin{array}{l}\text { qualitativa: } \\
\text { estudo de } \\
\text { caso; } \\
\text { - observações } \\
\text { e grupo focal; }\end{array}$ & $\begin{array}{l}\text { indicadores de altas habilidades/superdotação; } \\
\text { - identifica-se o PET como um recurso importante para a inclusão } \\
\text { destes acadêmicos; } \\
\text { - todos os alunos que participam dos grupos PETs observados } \\
\text { estão satisfeitos com sua escolha profissional }\end{array}$ \\
\hline $\begin{array}{l}\text { (DOMINGO } \\
\text { ALMEIDA; } \\
\text { BARRETO, } \\
\text { 2014) }\end{array}$ & 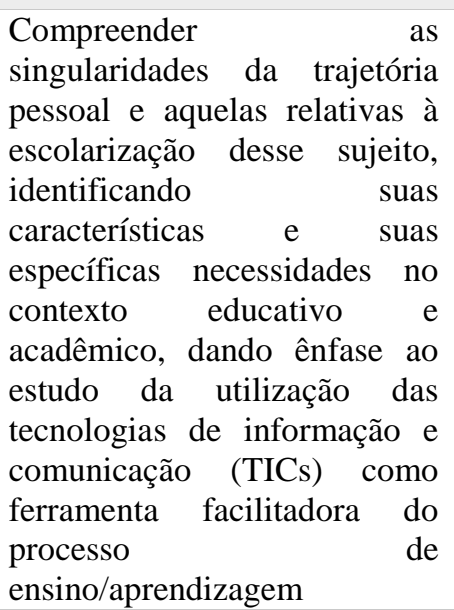 & $\begin{array}{l}\text { Um aluno com deficiência } \\
\text { visual }\end{array}$ & $\begin{array}{l}\text { Pesquisa de } \\
\text { natureza } \\
\text { qualitativa } \\
\text { exploratória. } \\
\text { Desenvolvida } \\
\text { a partir de } \\
\text { entrevista } \\
\text { semiestruturad } \\
\text { a. }\end{array}$ & $\begin{array}{l}\text { - despreparo do corpo docente em preparar o material para que o aluno } \\
\text { tenha acesso; } \\
\text { - eficiência no uso de tecnologias de Informação e Comunicação para } \\
\text { favorecer a inclusão. } \\
\text { - esforço do professor para escolarizar o aluno. O professores utilizou } \\
\text { e ensinou o aluno a usar os programas DOSVOX e JAWS }\end{array}$ \\
\hline $\begin{array}{l}\text { (LAMÔNIC } \\
\text { A et al., } \\
\text { 2008) }\end{array}$ & $\begin{array}{l}\text { Identificar, descrever e mapear } \\
\text { barreiras físicas no Campus da } \\
\text { Universidade de São Paulo de } \\
\text { Bauru e apresentar as } \\
\text { intervenções realizadas, } \\
\text { durante o período de outubro } \\
\text { de } 2001 \text { a dezembro de } 2005\end{array}$ & Não se aplica & Observações & $\begin{array}{l}\text { Dentro as barreiras encontradas destacam-se: Pontos de guias não } \\
\text { rebaixadas, pontos de acessos com diferenças de níveis sem rampas; } \\
\text { escadas/rampas sem corrimãos; escadas/rampas com corrimãos em } \\
\text { discordância com as normas vigentes; rampas com inclinações } \\
\text { superiores às determinadas nas normas técnicas; banheiros } \\
\text { parcialmente adaptados para deficientes; vagas de estacionamento } \\
\text { parcialmente adaptadas e elevadores existentes. Como intervenções } \\
\text { foram executados, rebaixamentos de guias, implementação piso tátil, } \\
\text { rampas; pontos de escadas e rampas externas instaladas com corrimãos } \\
\text { e guarda-corpos, vagas exclusivas no estacionamento; instalado } \\
\text { centrais de atendimento telefônico para surdo e adquiridas cadeira de } \\
\text { rodas. As intervenções realizadas contribuíram para melhorar a } \\
\text { acessibilidade de pessoas com deficiência no campus. }\end{array}$ \\
\hline $\begin{array}{l}\text { (FERREIRA, } \\
\text { 2007) }\end{array}$ & $\begin{array}{l}\text { Descrever o Programa de } \\
\text { Acompanhamento } \\
\text { Estudante com Necessidades }\end{array}$ & Não se aplica & $\begin{array}{l}\text { Relato de } \\
\text { experiência }\end{array}$ & $\begin{array}{l}\text { O programa é composto por profissionais oriundos das áreas de } \\
\text { Serviço Social, Educação e Psicologia, responsáveis por: a) identificar } \\
\text { as dificuldades e necessidades especiais concernentes ao processo de }\end{array}$ \\
\hline
\end{tabular}

Interfaces da Educ., Paranaíba, v.7, n.19, p.296-313, 2016. 


\begin{tabular}{|c|c|c|c|c|}
\hline & Educacionais Especiais & & & $\begin{array}{l}\text { ensino-aprendizagem-avaliação apresentadas pelo estudante e b) } \\
\text { propor recursos e estratégias que reduzam ou eliminem as dificuldades } \\
\text { e demandas especiais identificadas. Essas ações da equipe, associadas } \\
\text { a um trabalho de mediação junto aos colegiados de curso e demais } \\
\text { professores inseridos natuação, têm se mostrado eficazes para o bem } \\
\text { estar físico e emocional dos estudantes acompanhados, bem como para } \\
\text { a melhoria das condições indispensáveis à sua aprendizagem e } \\
\text { formação profissional qualificada, desde o ingresso até o final de sua } \\
\text { trajetória acadêmica }\end{array}$ \\
\hline $\begin{array}{l}\text { (BISOL et } \\
\text { al., 2010) }\end{array}$ & $\begin{array}{l}\text { Compreender a r vivência } \\
\text { universitária de estudantes } \\
\text { surdos que frequentaram } \\
\text { escolas bilíngues } \text { e se } \\
\text { identificam com a cultura } \\
\text { surda }\end{array}$ & $\begin{array}{l}\text { Cinco jovens matriculados } \\
\text { em cursos de graduação por } \\
\text { no mínimo três semestres }\end{array}$ & $\begin{array}{l}\text { Pesquisa de } \\
\text { campo / } \\
\text { entrevistas } \\
\text { individuais } \\
\text { semiestruturad } \\
\text { as. }\end{array}$ & $\begin{array}{l}\text { Os resultados descrevem o desafio da adaptação dos sujeitos surdos a } \\
\text { um universo majoritariamente ouvinte, as dificuldades de transitar } \\
\text { entre a língua de sinais e a língua portuguesa, a necessidade de manter } \\
\text { referenciais identitários valorizados aos olhos dos ouvintes, além da } \\
\text { importância de reorganizar as estratégias de ensino e de avaliar a } \\
\text { participação do intérprete de língua de sinais. }\end{array}$ \\
\hline
\end{tabular}




\subsection{Formação docente e inclusão no ensino superior}

Nos artigos analisados, a falta de formação especializada na área de inclusão escolar é uma evidência. No estudo realizado por Marques e Gomes (2014), a maioria dos professores universitários (11 de um total de 20 professores entrevistados) de uma Universidade Federal pontuaram o fato de que nunca tiveram acesso a uma palestra ou curso de formação. Nesse mesmo estudo os docentes reportaram o fato de que não tiveram oportunidades de lecionar para esse público de estudantes e desconheciam metodologias ou práticas pedagógicas para atendê-los. A falta de prepara por parte do corpo docente também é uma questão reportada no estudo de Domingos; Almeida e Barreto (2014), no qual um discente cego pontua o fato de que o corpo docente não estava preparado para adaptar materiais necessários para que ele tivesse acesso ao conteúdo.

No estudo de Lacerda e Gurgel (2011), os participantes possuem uma formação (intérpretes de libras) para atuar com a população surda, porém essa formação não ocorreu em espaços formais de ensino superior, como universidades, institutos federais. Vilela-Ribeiro e Benite (2011) atestam que essa falta de formação especializada sobre inclusão escolar, por parte dos docentes, decorre da fragilidade de seus currículos de formação inicial que não tratavam desse assunto.

Qualquer tipo de dificuldade que docentes venham a ter para garantir a plena inclusão desses estudantes no ensino superior é, principalmente, por conta de deficiências em seus currículos de formação inicial (VILELA-RIBEIRO; BENITE, 2011). E, pode-se pensar que essa deficiência não se estanca na licenciatura, isso porque sabe-se que atualmente para lecionar no ensino superior é exigido no mínimo uma titulação de mestrado e, na maioria das vezes, o título de doutor, dessa forma entende-se que nem mesmo a pós-graduação strictu sensu, ou seja, de longa duração e de caráter acadêmico, consegue garantir essa formação. Levando ao questionamento então, se existe algum outro tipo de formação continuada que consiga suprir essa demanda.

\subsection{Entraves para a inclusão no ensino superior}

Além da falta de formação especializada por parte dos docentes para lecionar a estudantes PAEE no ensino superior, outros entraves se somam e prejudicam a permanência desses estudantes na educação superior (DUARTE; FERREIRA, 2010). Uma das dificuldades 
recorrentes nos estudos (CRUZ; DIAS, 2009; BISOL et al., 2010), destinados especificamente ao público surdo, é a questão da comunicação. Isso acontece devido à ausência da proficiência (ou intérpretes) em LIBRAS entre docentes, colegas de turma e profissionais dos diversos setores da universidade. Vê-se ainda como dificuldades a questão de metodologias e avaliações sem flexibilidade (PEREIRA, 2008), as quais não levam em consideração uma sala de aula heterogênea.

As dificuldades oriundas da ausência da acessibilidade física e arquitetônica de prédios e ambientes externos é enfrentada, pincipalmente, por estudante com deficiência física e deficiência visual. Essa dificuldade foi relatada nos relatos de pesquisa de Cambruzzi, Costa e Denari (2013), Pereira (2008); Lamônica et al. (2008), como responsáveis por limitar o acesso dos estudantes aos ambientes de comum acesso e de convivência dentro da universidade como, por exemplo, restaurante universitário e biblioteca. A falta de acessibilidade também era evidenciada nos ônibus, assim como nos locais de embarque afastados e horários de tráfego limitados, dificultando o acesso e a circulação interna e externa ao campus.

No estudo de Lamônica et al., (2008), além de identificar os problemas de acessibilidade que interferiam negativamente no processo de inclusão na educação superior, os autores apresentaram as intervenções realizadas em busca de amenizar ou extinguir tais barreiras em busca de contribuir para melhorar a acessibilidade de pessoas com deficiência na universidade.

\subsection{Perfil dos discentes PAEE incluídos no ensino superior}

O estudo de Duarte e Ferreira (2010) destaca a questão do perfil de formação inicial desses estudantes ser, principalmente, na área de humanas. Dos estudos selecionados para essa revisão aqueles que apresentam como participantes alunos PAEE mesclam-se entre deficientes físicos, surdos, altas habilidades/superdotação, deficiência visual. Nota-se que estudantes com deficiência intelectual e transtornos globais do desenvolvimento não participam de nenhum estudo, o que nos faz questionar se estudantes com esses perfis não estão sendo incluídos ou simplesmente não fazem parte da amostra desse estudo devido aos critérios estabelecidos.

Os estudos de Duarte e Ferreira (2010) e Duarte et al. (2013), apresentam resultados de um mesmo estudo cujo objetivo foi realizar um levantamento de estudantes que se auto 
declaravam com deficiência. É interessante notar nesses resultados que a maioria dos estudantes que se declaravam encontravam-se na rede privada de ensino superior $(82,2 \%$ dos alunos). Nesse contexto, assim como as pesquisas desenvolvidas no ensino público (CAMBRUZZI; COSTA; DENARI, 2013; LAMÔNICA et al., 2008), vê-se a necessidade do desenvolvimento de pesquisas que investiguem a acessibilidade física e arquitetônica em instituições privadas de ensino superior no intuito de verificar as convergências e divergências em comparação com o ensino público, garantindo assim mais acesso e permanência com qualidade desse público de estudantes.

Inclusive porque a legislação que discorre sobre os núcleos de acessibilidade, por exemplo, restringe-se a universidades públicas, como foi pontuado na introdução do presente estudo.

\subsection{Outras informações relevantes}

Dois outros estudos selecionados, mas que não se enquadra nas demais categorias é o estudo desenvolvido por Manente, Rodrigues e Palamin (2007) no qual os autores investigam fatores que podem facilitar ou dificultar o ingresso de indivíduos com deficiência auditiva no ensino superior e sua permanência no curso. Os estudantes participantes do estudo apontaram como alguns dos fatores que favoreceram a inclusão no ensino superior o apoio de colegas da classe, dos familiares e atenção dos professores.

Domingos, Almeida e Barreto (2014) apresentam resultados de uma intervenção envolvendo o uso das tecnologias de Informação e Comunicação para favorecer a inclusão e ainda apresentam os esforços de um docente para escolarizar um estudante com deficiência visual oferecendo a ele auxílio para usar softwares como o DOSVOX e Jaws.

\section{CONSIDERAÇÕES FINAIS}

O desenvolvimento desse estudo permitiu traçar um panorama da inclusão de estudantes PAEE no ensino superior a partir de pesquisas publicadas em periódicos científicos. Os resultados apontam a escassez de pesquisas científicas nessa temática, contudo um aparente interesse constante e crescente nos últimos anos sobre o tema. Pode-se aferir esse interesse pelas maiores oportunidades que vêm sendo ofertadas aos estudantes a partir da implantação de programas como o Programa de Apoio a Planos de Reestruturação e Expansão 
das Universidades Federais (REUNI). Visto que mais pessoas estão conseguindo chegar e permanecer nas universidades e, a partir do momento que essas pessoas chegam, caso possuam deficiência, geram a demanda eminente de adaptações.

As barreiras encontradas pelos estudantes PAEE no âmbito do ensino superior, transpassam desde o ingresso até a permanência e sucesso na conclusão do curso. Notou-se que as barreiras físicas são as mais evidentes, uma vez que limitam o ir e vir dos alunos com deficiência visual e/ou física; metodologias diferenciadas de ensino, estratégias pedagógicas, assim como avaliações excludentes que não respeitam as especificidades individuais de todos os estudantes, especificidades estas não somente vinculadas as lesões físicas ou sensoriais, como também a dificuldades de aprendizagem; barreiras de comunicação, principalmente no caso do público surdo; docentes despreparados. Enfim, várias barreiras poderiam ser citadas, porém a presença desses estudos indicam que, embora ainda escassa, está havendo uma preocupação de pesquisadores científicos em investigar esse processo de inclusão no ensino superior.

Nesse contexto, vê-se a necessidade de explorar essa temática para que as principais dificuldades sejam evidenciadas de modo que se possa buscar de melhores condições para garantir a plena inclusão desses estudantes no ensino superior, assim como sua permanência com qualidade e, consequentemente, sucesso escolar. De modo que profissionais sejam formados e qualificados para atuarem nas diferentes esferas de trabalho, contribuindo com o desenvolvimento do país.

\section{REFERÊNCIAS}

BISOL et al. Estudantes surdos no ensino superior: reflexões sobre a inclusão. Cadernos de Pesquisa, v. 40, n. 139, p. 147-172, jan./abr. 2010.

BOTELHO, L, L. R.; CUNHA, C. C. A.; MACEDO, M. O método da revisão integrativa nos estudos organizacionais. Revista Gestão e Sociedade, Belo Horizonte, v. 5, n. 11. p. 121-136, mai./ago., 2011.

BRASIL. Constituição (1988). Constituição da República Federativa do Brasil. Brasília, DF, Senado, 1988.

Lei Federal n. 9394/96. Estabelece as Diretrizes e Bases da Educação Nacional, Brasília, 1996. 
BRASIL. Casal Civil. Subchefia para Assuntos Jurídicos. Lei 10.436, de 25 de abril de 2002. Dispõe sobre a Língua Brasileira de Sinais - LIBRAS e dá outras providências. Diário Oficial da União de 25/04/2002. Brasília, DF, 2002.

. Casal Civil. Subchefia para Assuntos Jurídicos. Decreto $n^{\circ}$ 5.296, de 2 de dezembro de 2004. Regulamenta as Leis nos 10.048, de 8 de novembro de 2000, que dá prioridade de atendimento às pessoas que especifica, e 10.098, de 19 de dezembro de 2000, que estabelece normas gerais e critérios básicos para a promoção da acessibilidade das pessoas portadoras de deficiência ou com mobilidade reduzida, e dá outras providências. Diário Oficial da União de 02/12/2004. Brasília, DF, 2004.

Casal Civil. Subchefia para Assuntos Jurídicos. Decreto $n^{\circ} .5 .626$, de 22 de dezembro de 2005. Regulamenta a Lei no 10.436, de 24 de abril de 2002, que dispõe sobre a Língua Brasileira de Sinais - Libras, e o art. 18 da Lei no 10.098, de 19 de dezembro de 2000. Diário Oficial da União de 23/12/2005. Brasília, DF, 2005. MEC, SEESP, 2008a.

Casal Civil. Subchefia para Assuntos Jurídicos. Decreto $n^{\circ} .6 .571$, de 17 de setembro de 2008. Dispõe sobre o atendimento educacional especializado, regulamenta o parágrafo único do art. 60 da Lei $\mathrm{n}^{\circ} 9.394$, de 20 de dezembro de 1996, e acrescenta dispositivo ao Decreto ${ }^{\circ}$ 6.253, de 13 de novembro de 2007. Publicado no DOU em 18 de setembro de 2008. Brasília, DF, 2008b.

. Casal Civil. Subchefia para Assuntos Jurídicos. Decreto $n^{\circ} 6.949$, de 25 de agosto de 2009. Promulga a Convenção Internacional sobre os Direitos das Pessoas com Deficiência e seu Protocolo Facultativo, assinados em Nova York, em 30 de março de 2007. Diário Oficial da União de 25/08/2009. Brasília, DF, 2009.

Casal Civil. Subchefia para Assuntos Jurídicos. Decreto $n^{o}$. 7.611, de 17 de novembro de 2011. Dispõe sobre a educação especial, o atendimento educacional especializado e dá outras providências. Brasília, DF, 2011.

. Ministério da Educação. Secretaria de Educação Continuada, Alfabetização, Diversidade e Inclusão. Secretaria de Educação Superior. Documento orientador Programa Incluir - Acessibilidade na educação superior. Brasília, DF, 2013. 21p.

CAMBRUZZI, S.; CÁSSIA, R.; COSTA, M. P. R.; DENARI, F. E. Acessibilidade de um cadeirante em uma instituição pública do ensino superior: rotas e rotinas. Revista de Educação Especial, Santa Maria, v. 26, n. 46. p. 351-366, mai./ago. 2013.

CASTANHO, D. M.; FREITAS, S. N. Inclusão e prática docente no ensino superior. Revista Educação Especial, Santa Maria, n.27, p. 85-92, 2006.

CRUZ, J. I. G.; DIAS, T. R. S. Trajetória escolar do surdo no ensino superior: condições e possibilidades. Revista Brasileira de Educação Especial, Marília, v. 15, n. 1, p. 65-80, jan./abr. 2009. 
DOMINGOS, R.; ALMEIDA, G. B. S.; BARRETO, S. M. C. O papel da Tecnologias de Informação e Comunicação (TICs) na inclusão de alunos com necessidades educacionais especiais no Centro Universitário do Espírito Santo - UNESC. Educação Por Escrito, Porto Alegre, v.5, n. 1, p. 98-110, jan./jun. 2014.

DUARTE, E. R. et al. Estudo de caso sobre a inclusão de alunos com deficiência no ensino superior. Revista Brasileira de Educação Especial, Marília, v. 19, n. 2, p. 289-300, abr./jun. 2013.

DUARTE, E. R.; FERREIRA, M. E. C. Panorama de inclusão de alunos com deficiência no ensino superior em Juiz de Fora, MG. Revista de Educação Especial, Santa Maria, v. 23, n. 36, p. 57-72, jan./abr. 2010.

FERREIRA, S. L. Ingresso, permanência e competência: uma realidade possível para universitários com necessidades educacionais especiais. Revista Brasileira de Educação Especial, Marília, v. 13, n. 1, p. 43-60, jan./abr. 2007.

JANNUZZI, G. S. M. A educação do deficiente no Brasil, dos primórdios ao início do século XXI. 2. ed. Campinas: Autores Associados, 2006. p. 244.

KASSAR, M. C. M. Política de educação especial no Brasil: escolha de caminhos. In: MENDES, E. G.; ALMEIDA, M. A. (Org.). A pesquisa sobre inclusão escolar em suas múltiplas dimensões: teoria, política e formação. Marília: ABPEE, 2012. p. 93-104.

LACERDA, C. B. F.; GURGEL, T. M. A. Perfil de tradutores-intérpretes de LIBRAS (TILS) que atuam no ensino superior no Brasil. Revista Brasileira de Educação Especial, Marilia, v. 17, n. 3, p. 481-496, set./dez. 2011.

LAMÔNICA, D. A. C. et al. Acessibilidade em ambiente universitário: identificação de barreiras arquitetônicas no campus da USP de Bauru, Revista Brasileira de Educação Especial, Marília, v. 14, n. 2, p. 177-188, mai./ago. 2008.

MANENTE, M. V.; RODRIGUES, O. M. P. R.; PALAMIN, M. E. G. Deficientes auditivos e escolaridade: fatores diferenciais que possibilitam o acesso ao ensino superior. Revista Brasileira de Educação Especial, Marília, v. 13, n. 1, p. 27-42, jan./abr. 2007.

MARQUES, L. S.; GOMES, C. Concordâncias/discordâncias acerca do processo inclusivo no Ensino Superior: um estudo exploratório. Revista de Educação Especial, Santa Maria, v. 27, n. 49, p. 313-326, maio/ago. 2014.

MENDES, E. G. A radicalização do debate sobre inclusão escolar no Brasil. Revista Brasileira de Educação Especial, v. 11, n. 33, p. 387-559, 2006.

PEREIRA, M. M. Inclusão no ensino superior: trajetórias acadêmicas dos alunos com deficiência que entraram na Universidade Estadual do Rio Grande do Sul pelo sistema de cotas. Revista de Educação Especial, v. 21, n. 32, p. 163-173, 2008. 
SASSAKI, R. Inclusão: a universidade e a pessoa com deficiência. Rede SACI, online, 19 de out 2006. Disponível em: <http://saci.org.br/?modulo=akemi\&parametro=18675>. Acesso em: nov. 2015.

VIEIRA, N. J. W. Identificação pela provisão: uma estratégia para a identificação das Altas Habilidades/Superdotação em adultos? Revista de Educação Especial, Santa Maria, v. 27, n. 50, p. 699-712, set./dez. 2014.

VILELA- RIBEIRO, E. B.; BENITE, A. M. C. Sobre a educação inclusiva na formação de professores de Ciências: a tessitura dos currículos praticados. Acta Scientiarum, Maringá, v. 33, n. 2, p. 239-245, 2011. 